\section{Analysis of Amaryllidaceae alkaloids from Zephyranthes grandiflora by GC/MS and their cholinesterase activity}

\author{
Lucie Cahlíková,", Irena Valterová, ${ }^{2}$ Kateřina Macáková, ${ }^{1}$ \\ Lubomír Opletal, ${ }^{1}$
}

${ }^{1}$ Department of Pharmaceutical Botany and Ecology, Faculty of Pharmacy, Charles University, Czech Republic,

${ }^{2}$ Institute of Organic Chemistry and Biochemistry of the AS CR, Czech Republic.

Abstract: Amaryllidaceae are known as ornamental plants, furthermore some species of this family contain galanthamine, an acetylcholinesterase inhibitor approved for the treatment of Alzheimer's disease, and other alkaloids with interesting pharmacological activity. The chemical composition of alkaloids from Zephyranthes grandiflora Lindl. was analyzed by GC/MS. Seven known compounds, belonging to five structural types of Amaryllidaceae alkaloids, were identified. The alkaloid extract from the bulbs showed promising cholinesterase inhibitory activities against human blood acetylcholinesterase (HuAChE; IC50 39.2 $\pm 3.0 \mu \mathrm{g} / \mathrm{mL}$ ) and human plasma butyrylcholinesterase (HuBuChE; IC50 356 $99.3 \mu \mathrm{g} / \mathrm{mL}$ ).
Revista Brasileira de Farmacognosia Brazilian Journal of Pharmacognosy 21(4): 575-580, Jul./Aug. 2011

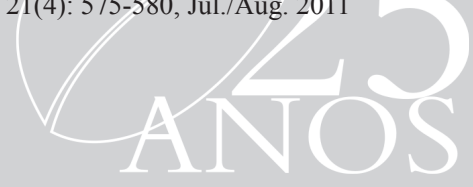

\section{Article}

Received 16 Sep 2010

Accepted 6 Nov 2010 Available online 20 May 2011

Keywords:

Amaryllidaceae acetylcholinesterase butyrylcholinesterase GC/MS

Zephyranthes grandiflora

ISSN 0102-695X doi: 10.1590/S0102-695X2011005000089

\section{Introduction}

Plants of the Amaryllidaceae family are well-known for their ornamental value but also for the alkaloids they produce. The chemical structures of these alkaloids are very variable as well as their pharmacological properties. Some species of this family contain galanthamine, an acetylcholinesterase inhibitor approved for the treatment of Alzheimer's disease (AD) (Hostettman et al., 2006), as well as other alkaloids with interesting pharmacological activities: antimalarial, antiviral and antiproliferative (Campbell et al., 1988; Hohmann et al., 2002; Szlávik et al., 2004).

$\mathrm{AD}$ is the most predominant cause of dementia in the elderly. Epidemiological data indicate a potentially considerable increase in the prevalence of the disease over the next two decades (Johnson et al., 2000). In AD patients, deficit of cholinergic functions, which results in decreased levels of the neurotransmitter acetylcholine $(\mathrm{ACh})$ in the cortex, is responsible for the memory impairments (Lahiri et al., 2002). The principal role of acetylcholinesterase (AChE) is the termination of nerve impulse transmission at the cholinergic synapses by rapid hydrolysis of ACh. Inhibition of AChE serves as a strategy for the treatment of $\mathrm{AD}$, senile dementia, ataxia, myasthenia gravis, and Parkinson's disease (Rahman \& Coudhary, 2001). In the healthy brain $\mathrm{AChE}$ is the most important enzyme regulating the level of ACh while other enzyme, butyrylcholinesterase (BuChE) plays only minor role. Moreover, in late AD stages, levels of AChE have declined by up to $85 \%$ and BuChE represents the predominant cholinesterase in the brain. BuChE, primarily associated with glial cells, but also with specific neuronal pathways, cleaves ACh in a manner similar to that of $\mathrm{AChE}$ to terminate its physiological action (Greig et al., 2002). Galanthamine has been shown to be much less potent against BuChE than AChE activity (Fulton \& Benfield, 1996). This fact has targeted BuChE as a new approach to intercede in the progression of $\mathrm{AD}$ and requires research of new inhibitors with dual enzymatic activity. Currently, cholinesterase inhibition is the most used therapeutic treatment for the symptoms of AD (Lleó, 2007; Recanatini \& Valenti, 2004). In recent years some overviews of natural product inhibitors of $\mathrm{AChE}$ were reported (Barbosa-Filho et al., 2006; Hostettmann et al., 2006).

Species of Zephyranthes are widely used as a folk medicine in many countries. The decoction of leaves of $Z$. candida has been used in South Africa as a remedy for diabetes mellitus and $Z$. parulla appears in 
the history of Peru as a treatment for tumors (Pettit et al., 1984). Z. rosea and Z. flava are used for a variety of therapeutic purposes in India (Ghosal et al., 1985; Ghosal et al., 1986).

There have been few phytochemical studies of Zephyranthes species, and only two GC/ MS investigations. From Z. citrina, eight alkaloids (galanthine, haemanthamine, lycorine, lycorenine, oxomaritidine, maritidine, vittatine, and narcissidine) have been isolated (Boit et al, 1957; Herrera et al., 2001). In addition to these, zefbetaine and zeflabetaine were isolated from Z. flava (Ghosal et al., 1986), and pretazettine and carinatine, along with lycorine, galanthine and haemanthanine from $Z$. carinata (Kobayashi et al., 1977). Previous phytochemical investigation of $Z$. grandiflora led to the isolation of pancratistatin (Pettit et al., 1984). GC/MS analysis of the bulb extracts of $Z$. concolor and $Z$. robusta showed the domination of galanthamine-type Amaryllidaceae alkaloids and these extracts possessed promising AChE inhibitory activity (Berkov et al., 2008; Cahlíková et al., 2010).

Alkaloids of many different skeleton types can be rapidly identified by GC/EI-MS (Wink et al., 1995; Kreh et al., 1995; Suau et al., 2002). It has been found that Amaryllidaceae alkaloids can be analyzed by GC without derivatization and, with only few exceptions, they show a mass spectral fragmentation pattern very similar to those obtained under direct insertion (Kreh et al., 1995). Several studies of the distribution of galanthamine in different subspecies and populations of mainly Galanthus and Narcissus species have been published (Lopéz et al., 2002; Berkov et al., 2004). GC/MS analysis has been successfully applied for the reliable and fast identification of Amaryllidaceae alkaloids and for comparative study of their percentage contribution in the alkaloid mixtures (Berkov et al., 2008).

\section{Materials and Methods}

\section{Plant material}

The fresh bulbs of Zephyranthes grandiflora Lindl., Amaryllidaceae, were obtained from Lukon Glads (Sadská, Czech Republic). The botanical identification was performed by Assoc. Prof. Lubomír Opletal, CSc. A voucher specimen is deposited in the herbarium of the Faculty of Pharmacy at Hradec Králové.

\section{Extraction of alkaloids}

Fresh bulbs ( $3 \times 15 \mathrm{~g})$ were extracted three times with $\mathrm{EtOH}(50 \mathrm{~mL})$ at room temperature for 24 h. The solvent was evaporated under reduced pressure and the residue dissolved in $10 \mathrm{~mL} 2 \% \mathrm{HCl}$. After removing the neutral compounds with diethyl ether (3 x $15 \mathrm{~mL}$ ), the extract was basified with $25 \%$ ammonia solution and the alkaloids extracted with EtOAc $(3 \times 15$ $\mathrm{mL}$ ). The organic solvent was evaporated and $10 \mathrm{mg}$ of each alkaloid extract removed for acetylcholinesterase and butyrylcholinesterase assay. The rest of the dry alkaloid fraction was dissolved in $\mathrm{MeOH}$ to a final concentration of $10 \mathrm{mg} / \mathrm{mL}$ for further analysis.

\section{GC/MS analysis}

The GC/MS analysis of underivatized alkaloids from $Z$. grandiflora was carried out on a gas chromatograph (Focus Thermo Scientific, USA) with a splitless injector $\left(280{ }^{\circ} \mathrm{C}\right)$ and a mass detector $\left(200{ }^{\circ} \mathrm{C}\right.$, GC-MS MD 800 Fisons, Manchester, UK). A DB-5MS column (30 m x $0.25 \mathrm{~mm} \times 0.25 \mu \mathrm{m}$, Agilent Technologies Santa Clara, CA, USA) and helium gas (constant flow $1 \mathrm{~mL} / \mathrm{min}$ ) were used for separation. The temperature program was: $100-180{ }^{\circ} \mathrm{C}$ at $15{ }^{\circ} \mathrm{C} /$ min, $1 \mathrm{~min}$ hold at $180{ }^{\circ} \mathrm{C}$ and $180-300{ }^{\circ} \mathrm{C}$ at $5^{\circ} \mathrm{C} / \mathrm{min}$ and $5 \mathrm{~min}$ hold at $300{ }^{\circ} \mathrm{C}$, detection range $\mathrm{m} / \mathrm{z} 40-600$. The injector temperature was $280{ }^{\circ} \mathrm{C}$. The alkaloids were identified by comparison of their MS with those in the NIST library, with those reported in the literature (Berkov et al., 2008; Gotti et al., 2006; Kreh et al., 1995; López et al., 2002), with commercially available standards (galanthamine, Changsha Organic), and with reference compounds isolated earlier in our laboratory (galanthamine, galanthine, lycoramine, haemanthamine, vittatine, and tazettine).

\section{Preparation of red blood cells ghost}

Ghosts were prepared from freshly drawn blood (taken from healthy volunteers), to which 1 $\mathrm{mL}$ of sodium citrate per $10 \mathrm{~mL}$ of blood was added, according to a slightly modified method of Steck and Kant (Steck \& Kant, 1974). Briefly plasma (HuBuChE) was removed from the whole blood by centrifugation at $4000 \mathrm{rpm}$ in a Boeco U-32R centrifuge with a Hettich 1611 rotor. Red blood cells were transferred to $50 \mathrm{~mL}$ tubes and washed three times with $5 \mathrm{mM}$ phosphate buffer ( $\mathrm{pH}$ 7.4) containing $150 \mathrm{mM}$ sodium chloride (12000 rpm, Avanti J-30I, rotor JA-30.50). The washed erythrocytes were stirred with $5 \mathrm{mM}$ phosphate buffer (pH 7.4) for $10 \mathrm{~min}$ to ensure lysis. The lysed cells were centrifuged at 20,000 rpm for $10 \mathrm{~min}$ and then the ghosts (HuAChE) were washed three times with phosphate buffer.

Acetylcholinesterase and butyrylcholinesterase assay 
HuAChE and HuBuChE activities were determined with a modified method of Ellman et al. (Ellman et al., 1961) at concentrations 2.5, 25, and $250 \mu \mathrm{m} / \mathrm{L}$ using acetylthiocholine iodide and butyrylthiocholine iodide as substrates, respectively. Briefly, 25-50 $\mu \mathrm{L}$ of either ghosts or plasma, $650 \mu \mathrm{L}$ of DTNB and $25 \mu \mathrm{L}$ of either the sample or appropriate solvent, as a blank sample, were added to the semimicro cuvette. The reaction was initiated by addition of substrate (ATChI or BuTChI). The final proportion of DTNB to substrate was $1: 1$. The increase of absorbance at $436 \mathrm{~nm}(\triangle \mathrm{A})$ was measured for 1 min using a Shimadzu UV-1611 spectrophotometer. Each measurement was repeated three times. Galanthamine and huperzine A were used as positive standards (Cahlíková et al., 2010). The inhibition (in \%) was calculated according to the formula: $\% \mathrm{I}=100-\left(\Delta \mathrm{A}_{\mathrm{BL}} / \Delta \mathrm{A}_{\mathrm{SA}}\right) \times 100$, where $\Delta \mathrm{A}_{\mathrm{BL}}$ is increase of absorbance of a blank sample and $\Delta \mathrm{A}_{\mathrm{SA}}$ is increase of absorbance of the measured sample.

\section{Statistical analysis}

The IC50 values were calculated with the use of GraphPad Prism 5.02 software.

\section{Results and Discussion}

In the present work we report the GC/MS investigation of the alkaloid extract from the bulbs of Z. grandiflora and the inhibitory effect of this extract on the activity of human erythrocytic AChE (HuAChE) and plasma BuChE (HuBuChE).

The ethanolic extract from Z. grandiflora bulbs inhibited $\mathrm{HuAChE}$ and $\mathrm{HuBuChE}$ at a concentration of $500 \mu \mathrm{g} / \mathrm{mL}(65.5 \pm 4.0 \%$ for $\mathrm{HuAChE}$ and $25.0 \pm 2.2 \%$ for
$\mathrm{HuBuChE}$ ), thus indicating the presence of cholinesterase inhibitors in this plant taxon. The crude extract from the bulbs was separated into alkaloid fraction and, as expected, the alkaloid fraction possessed a promising activity with IC50 value $39.2 \pm 3.0 \mu \mathrm{g} / \mathrm{mL}$ for HuAChE and $356 \pm 9.3 \mu \mathrm{g} /$ $\mathrm{mL}$ for $\mathrm{HuBuChE}$ (Table 1).

Table 1. HuAChE and HuBuChE inhibitory activity of the alkaloid extract of Zephyranthes grandiflora.

\begin{tabular}{|c|c|c|}
\hline $\begin{array}{l}\text { Concentration } \\
(\mu \mathrm{g} / \mathrm{mL})\end{array}$ & $\begin{array}{c}\text { HuAChE }^{\mathrm{a}} \\
\text { inhibition (\%) }\end{array}$ & $\begin{array}{l}\mathrm{HuBuChE}^{\mathrm{a}} \\
\text { inhibition (\%) }\end{array}$ \\
\hline 500 & $90.6 \pm 5.5$ & $57.2 \pm 3.2$ \\
\hline 250 & $85.7 \pm 4.7$ & $39.9 \pm 2.9$ \\
\hline 125 & $75.1 \pm 3.9$ & $23.6 \pm 1.8$ \\
\hline 25 & $38.1 \pm 4.4$ & $4.4 \pm 0.4$ \\
\hline 12.5 & $23.6 \pm 2.8$ & $2.1 \pm 0.2$ \\
\hline 2.5 & $5.01 \pm 0.5$ & 0 \\
\hline 0.25 & 0 & 0 \\
\hline IC50 $(\mu \mathrm{g} / \mathrm{mL})$ & $39.2 \pm 3.0$ & $356 \pm 9.3$ \\
\hline IC $50^{c}$ Galanthamine $^{\mathrm{b}}$ & $6.9 \pm 0.3$ & $156 \pm 6.9$ \\
\hline IC50 ${ }^{\mathrm{c}}$ Huperzine $\mathrm{A}^{\mathrm{b}}$ & $0.25 \pm 0.01$ & $>1000$ \\
\hline
\end{tabular}

${ }^{\mathrm{a}}$ Results are the mean of three replications; ${ }^{\mathrm{b}}$ Reference compounds; ${ }^{\mathrm{c}}(\mu \mathrm{M})$

In order to identify the compounds in the complex alkaloid fraction of bulbs of $Z$. grandiflora, a capillary GC/MS was employed. In the bulb extract, seven alkaloids of five structural types were detected by GC (Figure 1) and identified from their retention times (RT) and mass spectra as galanthamine (1, galanthaminetype), lycoramine (2, galanthamine-type), vittatine (3, haemanthamine-type), nerbowdine (4, crinine-type), haemanthamine $(\mathbf{5}$, haemanthamine-type), tazzetine $(\mathbf{6}$, tazzetine-type), and galanthine (7, lycorine-type). The relative proportion of each alkaloid was determined

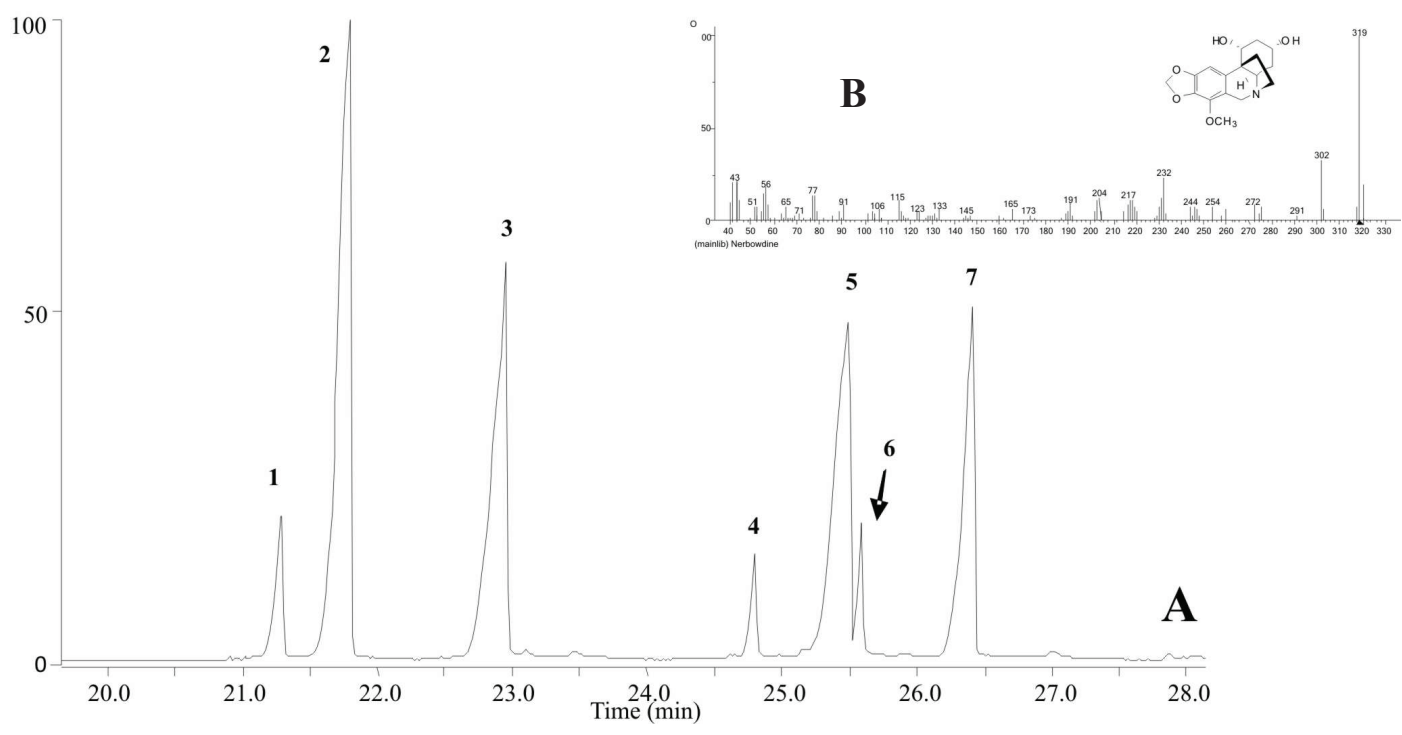

Figure 1. GC/MS of the Zephyranthes grandiflora alkaloid fraction (A) and MS spectrum of nerbowdine (B). 
<smiles>COc1ccc2c3c1OC1CC(O)C=CC31CCN2C</smiles>

Galanthamine (1)<smiles>CN1Cc2cccc3c2C2(CCC(O)CC2O3)C1</smiles>

Lycoramine (2)

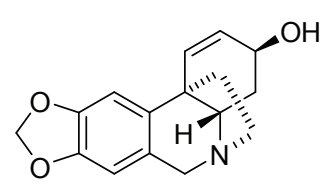

Vittatine (3)<smiles></smiles>

Nerbowdine (4)

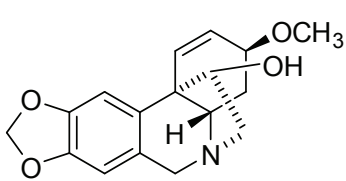

Haemanthamine (5)<smiles>CO[C@H]1C=C[C@]2(COCc3cc4c(cc32)OCO4)[C@H](O)N1C</smiles>

Tazettine (6)<smiles></smiles>

Galanthine (7)

Table 2. Alkaloids identified by GC/MS in bulbs of Zephyranthes grandiflora.

\begin{tabular}{|c|c|c|c|c|}
\hline Compound & $\mathrm{RT}^{\mathrm{a}},(\min )$ & $\begin{array}{c}{\left[\mathrm{M}^{+}\right] \text {and characteristic ions, } m / z} \\
\text { (\% relative intensity) }\end{array}$ & $\%{ }^{\mathrm{b}}$ & Reference for MS data \\
\hline 1 Galanthamine & 21.29 & 287(90), $286(100), 270(20), 244(30), 230(5), 216(45)$ & 5 & NIST 08, $\mathrm{st}^{\mathrm{c}}$ \\
\hline 2 Lycoramine & 21.79 & 289 (65), 288 (100), 274 (10), $232(10), 202(30)$ & 30 & NIST $08, \mathrm{st}^{\mathrm{c}}$ \\
\hline 3 Vittatine & 22.94 & $271(100), 252(30), 199(90), 187$ (95), $173(30)$ & 21 & NIST $08, \mathrm{st}^{\mathrm{c}}$ \\
\hline 4 Nerbowdine & 24.79 & $319(100), 302(50), 272(30), 254(45), 232(75)$ & 3 & NIST 08 \\
\hline 5 Haemanthamine & 25.49 & $301(20), 272(100), 240(15), 225(10), 211(15)$ & 23 & NIST $08, \mathrm{st}^{\mathrm{c}}$ \\
\hline 6 Tazettine & 25.59 & $331(20), 316(20), 298(30), 247(100)$ & 2 & NIST $08, \mathrm{st}^{\mathrm{c}}$ \\
\hline 7 Galanthine & 26.40 & 317 (30), 298 (15), 284 (15), 268 (15), 243 (100), 242 (95) & 16 & NIST $08, \mathrm{st}^{\mathrm{c}}$ \\
\hline
\end{tabular}

${ }^{a}$ For GC conditions see the Materials and methods section; ${ }^{\mathrm{b}}$ Values are expressed as a percentage of the total ion current (TIC); ${ }^{\mathrm{c}}$ Standart.

as a percentage of the total ion current. The alkaloid pattern of bulbs of $Z$. grandiflora was dominated by lycoramine $(2 ; 30 \%$ of $\mathrm{TIC})$, haemanthamine $(5 ; 23$ $\%$ of TIC) and vittatine (3, $21 \%$ of TIC) (Table 2). The area of the GC/MS peaks depends not only on the corresponding compounds, but also on the intensity of their MS fragmentation (response factor). Thus, the data given in the table are not true quantification. However, they can be used for comparison between samples.

Galanthamine (1) is a long-lasting, selective, reversible and competitive $\mathrm{AChE}$ inhibitor, which has been isolated or described in various genera of Amaryllidaceae plant species (Amaryllis, Galanthus, Leucojum, Pancratium, Zephyranthes etc.) (Park, 2010). It is a good example of a natural product substituting synthetic drugs in the treatment of AD. Although lycoramine (2) is a galanthamine-type, its AChE inhibition activity is very low (Lopéz et al., 2002). Nerbowdine (4) is a relatively rare alkaloid, which has been isolated before from two Crinum sp. (C. moorei and C. erubescens), from Boophone disticha (Wildman et al., 1967; Lyle et al., 1960; Haut \& Stauffacher, 1961), and once identified by GC/MS technique in Zephyranthes robusta (Cahlíková et al., 2010). There are no data on biological activities of this compound, but alkaloids of the crinane-type have been shown to exhibit a range of biological activities including antimalarial and antiproliferative action as well as protein synthesis inhibition (Tram et al., 2002). Heamanthamine (5) and tazettine (6) are common alkaloids in family Amaryllidaceae. Both alkaloids were tested for their AChE inhibition activity, but they were considered inactive (Lopéz et al., 2002). Galanthine (7) is also a common Amaryllidaceae alkaloid, but it occurs mainly as a minor component. Hitherto no data on the inhibitory effect of this compound on the AChE have been reported. However, this alkaloid, together with oxomaritine (vittatine-type), both isolated from Zephyranthes citrina, has shown a moderate activity in vitro against Trypanosoma brucei rhodesiense with IC50 value of 3.1 and $2.8 \mu \mathrm{g} / \mathrm{mL}$, respectively (Herrera et al., 2001).

Twenty-three alkaloids isolated from various Amaryllidaceae species have been previously studied for their in vitro AChE inhibitory activity with galanthamine as a positive control. The results of these studies showed, that the AChE inhibitory activity is associated mainly with galanthamine- and lycorine-type of alkaloids (Lopéz et 
al., 2002; Houghton et al., 2006; Hostettman et al., 2006). Lycorine-type compounds are less active inhibitors than the galanthamine type compounds and their activity is associated with a substitution at position in C-1 and C-2 (Houghton et al., 2006). Therefore, the presence of the above mentioned compounds could explain the AChE inhibitory activity of the extract of $Z$. grandiflora.

GC/MS analysis of bulbs of $Z$. concolor showed that galanthamine-type alkaloids represented more than $90 \%$ of the alkaloid mixture, which inhibited AChE from electric eel, using TLC bioautographic assay, by $88 \pm 0.2 \%$ at a concentration of $10 \mu \mathrm{g} / \mathrm{mL}$. Galanthamine (64\%) and chlidanthine (24\%), both galanthamine-type, were identified as the main components (Berkov et al., 2008). In our study, galanthamine (1) was present only as a minor component $(5 \%)$, and chlidanthine has not be detected. In comparison with our previous phytochemical investigation on $Z$. robusta, we identified a very similar alkaloidal profile and inhibition activity to $\mathrm{HuAChE}$ and HuBuChE (Cahlíková, et al., 2010). Although we found the same compounds, the main differences were in the content (TIC) of galanthine (7) and haemanthamine (5). The alkaloid pattern of $Z$. robusta was dominated by galanthine (7), which was present only in a small amount in Z. grandiflora.

As mentioned, BuChE plays an important role in the late AD stages, but only a limited number of alkaloids has been tested for their BuChE inhibitory activity so far. The screening of crude and/or alkaloid extracts from plants, followed by GC/MS analysis, seems to be a good way for searching of new bioactive natural compounds with $\mathrm{AChE} / \mathrm{BuChE}$ inhibition activity. In case of identification of unknown structures by GC/MS, the isolation of these compounds would be interesting due to its potential activity as cholinesterase inhibitors.

\section{Acknowledgment}

This project was supported by the grants SVV2010-261-002, GA UK 122309 and Research Project Z40550506 (AS CR).

\section{References}

Barbosa-Filho JM, Medeiros KCPM, Diniz MFFM, Batista LM, Athayde-Filho PF, Silva MS, da-Cunha EVL, Almeida JRGS, Quintans-Júnior LJ 2006. Natural products inhibitors of the enzyme acetylcholinesterase. Rev Bras Farmacogn 16: 258-285.

Berkov S, Sidjimova B, Evstatieva L, Popov S 2004. Intraspecific variability in the alkaloid metabolism of Galanthus elwesii. Phytochemistry 65: 579-586.

Berkov S, Bastida J, Nikolova M, Viladomat F, Codina C 2008. Rapid TLC/GC-MS identification of acetylcholinesterase inhibitors in alkaloid extract. Phytochem Anal 19: 411419.
Boit HG, Döpke W, Stender W 1957. Alkaloide aus Crinum, Zephyranthes, Leucojum und Clivia Arten. Chem Ber 90: 2203-2206.

Cahlíková L, Kulhánková A, Urbanová K, Valterová I, Macáková K, Kuneš J 2010. Analysis of Amaryllidaceae alkaloids from Zephyranthes robusta by GC-MS and their cholinesterase activity. Nat Prod Comm 5: 12011204.

Campbell WE, Nair JJ, Gammon DW, Bastida J, Codina C, Viladomat F, Smith PJ, Albrecht CF 1988. Cytotoxic and antimalarial alkaloids from Brunsvigia littoralis. Planta Med 64: 91-93.

Ellman GL, Courtney KD, Andres VJr, Featherstone RM 1961. A new rapid colorimetric determination of acetylcholinesterase activity. Biochem Pharmacol 7: 8895.

Fulton B, Benfield P 1996. Galanthamine. Drugs Aging 9: 6065.

Ghosal S, Singh SK, Srivastava RS 1985. Chemical constituents of Amaryllidaceae. Part 9. (+)-Epimaritidine, an alkaloid from Zephyranthes rosea. Phytochemistry 24: 635-637.

Ghosal S, Singh SK, Srivastava RS 1986. Chemical constituents of Amaryllidaceae. Part 22. Alkaloids from Zephyranthes flava. Phytochemistry 25: $1975-$ 1978.

Gotti R, Fiori J, Bartolini M, Cavrini V 2006. Analysis of Amaryllidaceae alkaloids from Narcissus by GC-MS and capillary electrophoresis. J Pharm Biomed Anal 42: 17-24.

Greig NH, Lahiri DK, Sambamurti K 2002. Butyrylcholinesterase: an important new target in Alzheimer's disease therapy. Int Psychogeriatr 14: 77-91.

Hauth H, Stauffacher D 1961. Die Alkaloide von Boophone disticha (L.f.) Herb. Helv Chim Acta 44: 491-502.

Herrera MR, Machocho AK, Brun R, Viladomat F, Codina C, Bastida J 2001. Crinane and lycorane type alkaloids from Zephyranthes citrina. Planta Med 67: 191-193.

Hohmann J, Forgo P, Molnár J, Wolfard K, Molnár A, Thalhammer T, Máthé I, Sharples D 2002. Antiproliferative Amaryllidaceae alkaloids isolated from the bulbs of Sprekelia formosissima and Hymenocalis $x$ festalis. Planta Med 68: 454-457.

Hostettmann K, Borloz A, Urbain A, Marston A 2006. Natural product inhibitors of acetylcholinesterase. Curr Org Chem 10: 825-847.

Houghton P, Ren Y, Howes MJ 2006. Acetylcholinesterase inhibitors from plants and fungi. Nat Prod Rep 23: 181189.

Johnson N, Davis T, Bosanquet N 2000. The epidemic of Alzheimer's disease; how can we manage the costs? Pharmacoeconomics 18: 215-223.

Kobayashi S, Ishikawa H, Kihara M, Shingu T, Hashimoto T 1977. Isolation of carinatine and pretazettine from the bulbs of Zephyranthes carinata Herb. (Amaryllidaceae). Chem Pharm Bull 25: 2244-2248.

Kreh M, Matusch R, Witte L 1995. Capillary gas chromatographymass spectrometry of Amaryllidaceae alkaloids. Phytochemistry 38: 773-776

Lahiri DK, Farlow MR, Greig NH, Sambamurti K 2002. Current 
drug targets for Alzheimer's disease treatment. Drug Develop Res 56: 267-281.

Lleó A 2007. Current therapeutic options for Alzheimer's disease. Curr Genomics 8: 550-558.

López S, Bastida J, Viladomat F, Codina C 2002. Acetylcholinesterase inhibitory activity of same Amaryllidaceae alkaloids and Narcissus extracts. Life Sci 71: 2521-2529.

Lyle RE, Kielar EA, Crowder JR, Wildman WC 1960. Alkaloids of Amaryllidaceae XV. The alkaloids of Nerine bowdenii W. Wats. and Crinum moorei J. D. Hook. J Am Chem Soc 82: 2620-2625.

Park SY 2010. Potential therapeutic agents against Alzheimer's disease from natural sources. Arch Pharm Res 33: 15891609.

Pettit GR, Gaddamidi V, Cragg GM 1984. Antineoplastic agents, 105. Zephyranthes grandiflora. J Nat Prod 47: 10181020.

Rahman AU, Coudhary MI 2001. Bioactive natural products as a potential source of new pharmacophores a theory of memory. Purr Appl Chem 73: 555-560.

Recanatini M, Valenti P 2004. Acetylcholinesterase inhibitors as a starting point towards improved Alzheimer's disease therapeutics. Curr Pharm Design 10: 3157-3166.

Steck TL, Kant JA 1974. Preparation of impermeable ghosts and inside-out vesicles from human erythrocyte membranes. Method Enzymol 31 (Pt A): 172-180.
Suau R, Cabezudo B, Rico R, Najera F, López-Romero J 2002. Direct determination of alkaloid contents in Fumaria species by GC-MS. Phytochem Anal 13: 363-367.

Szlávik L, Gyuris Á, Minárovits J, Forgo P, Molnár J, Hohmann J 2004. Alkaloids from Leucojum vernum and antiretroviral activity of Amaryllidaceae alkaloids. Planta Med 70: 871-873.

Tram NTN, Titorenkova TV, Bankova VS, Handjieva NV, Popov SS 2002. Crinum L. (Amaryllidaceae). Fitoterapia 73: 183-208.

Wildman WC, Brown CL, Michel KH, Bailey DT, Heimer NE, Schaffer R, Murphy CF 1967. Alkaloids from Rhodophiala bifida, Crinum erubescens and Sprekelia formisissima. Pharmazie 22: 725.

Wink M, Meisner C, Witte L 1995. Pattern of quinolizidine alkaloids in 56 species of the genus Lupinus. Phytochemistry 38: 139-153.

\section{*Correspondence}

Lucie Cahlíková

Department of Pharmaceutical Botany and Ecology, Faculty of Pharmacy, Charles University

Heyrovského 1203, 50005 Hradec Králové, Czech Republic cahlikova@faf.cuni.cz

Tel. +420495067303

Fax: +420495518002 